\title{
PENINGKATAN KEMAMPUAN PEMECAHAN MASALAH MATEMATIS (KPMM) MELALUI MODEL SAVI (SOMATIC, AUDITORY, VISUAL AND INTELLECTUAL) DENGAN GEOMETER'S SKETCHPAD
}

\author{
Fazrina Saumi ${ }^{1}$, Rizki Amalia ${ }^{2}$, Amelia $^{3}$, Ari Hestaliana. $\mathbf{R}^{4}$ \\ Universitas Samudra, Jln Kampus Meurandeh, Langsa Lama, Kota Langsa, Aceh ${ }^{1,2,3}$ \\ STKIP An-Nur, T. Lamgugop, Banda Aceh. Aceh ${ }^{4}$ \\ e-mail: fazrinasaumi@unsam.ac.id
}

\begin{abstract}
ABSTRAK
Pembelajaran geometri perlu menggunakan model dan software yang sesuai untuk mengembangkan kemampuan pemecahan masalah matematis. Salah satunya adalah dengan model SAVI (Somatic, Auditory, Visual and Intellectual) yang dipadukan dengan penggunaan software Geometer's Sketchpad. Tujuan penelitian ini untuk menganalisis perbedaan yang signifikan antara kemampuan pemecahan masalah yang belajar di kelas pembelajaran Model SAVI dengan Geometer's Sketchpad dan mahasiswa yang belajar di kelas pembelajaran pembelajaran Model SAVI tanpa Geometer's Sketchpad. Metode penelitian yang dilaksanakan adalah penelitian kuantitatif dengan pretest-postest Nonequivalent Control Group Design. Kelas geometri FKIP matematika sebagai kelas kontrol dan kelas geometri MIPA matematika sebagai kelas eksperimen. Instrumen yang digunakan adalah soal tes KPMM pada materi geometri. Berdasarkan uji $\mathrm{t}$ diperoleh nilai sig. (2-tailed) yaitu 0,002 dan menunjukkan kurang dari 0,05 sehingga $\mathrm{H}_{0}$ ditolak, dapat disimpulkan adanya perbedaan yang signifikan antara data $\mathrm{N}$-gain KPMM yang belajar di kelas pembelajaran Model SAVI dengan Geometer's Sketchpad dan mahasiswa yang belajar di kelas pembelajaran pembelajaran Model SAVI tanpa Geometer's Sketchpad.
\end{abstract}

Kata kunci :

Geometer's Sketchpad, Pemecahan masalah, model SAVI.

\begin{abstract}
Learning geometry needs to use appropriate models and software to develop KPMM. One of them is the SAVI model (Somatic, Auditory, Visual and Intellectual) which is combined with the use of Geometer's Sketchpad software. This study aims to analyze significant differences between the Ngain data of problem-solving abilities studied in the SAVI Model learning class with Geometer's Sketchpad and students who study in the SAVI Model learning class without Geometer's Sketchpad. The research method used was quantitative research with the pretest-posttest Nonequivalent Control Group Design. FKIP mathematics geometry class as a control class and MIPA Mathematics geometry class as an experimental class. The instrument used was a matter KPMM tests on geometry material. Based on the t-test, the value of sig is obtained. (2-tailed) that is 0.002 and shows smaller than 0.05 so that $H_{0}$ is rejected, it can be concluded that there is a significant difference between the N-gain data of the KPMM to learn in the SAVI Model learning class with Geometer's Sketchpad and students studying in the learning class SAVI learning model without Geometer's Sketchpad.
\end{abstract}

Keywords :

Geometer's Sketchpad, Problem Solving, SAVI Model.

\section{PENDAHULUAN}

Geometri merupakan materi matematika yang diajarkan melalui pendidikan dasar, menengah dan tinggi. Pembelajaran geometri penting diajarkan karena sangat mendukung materi lainnya dalam matematika maupun di bidang ilmu lain. Selain itu, dalam mempelajari geometri peserta didik juga diharapkan dapat mengembangkan KPMM.

Suydam (dalam Clements \& Battista, 1992) menyatakan bahwa tujuan pembelajaran geometri adalah:

“(1) mengembangkan kemampuan berpikir logis, (2) mengembangkan intuisi spasial mengenai dunia nyata, (3) menanamkan pengetahuan yang 
dibutuhkan untuk matematika lanjut, dan (4) mengajarkan cara membaca dan menginterpretasikan argumen matematika.

Selanjutnya

Bobango

(1993)

mengemukakan bahwa pembelajaran geometri bertujuan agar peserta didik: (1) meningkatkan rasa percaya diri pada kemampuan matematikanya, memperoleh solusi yang baik, (3) kemampuan berkomunikasi secara matematik meningkat, dan (4) kemampuan bernalar secara matematik meningkat. Shadiq (2004) berpendapat bahwa KPMM sangat menentukan tingkat kesuksesan peserta didik dalam pembelajaran matematika. Tentunya juga berdampak terhadap implementasi pengetahuan peserta didik di kehidupan bermasyarakat nantinya. Oleh karena itu, pengintegrasian KPMM selama proses pembelajaran berlangsung merupakan suatu yang urgen dilaksanakan.

Namun, pada tingkat perguruan tinggi misalnya, KPMM masih minim diintegrasikan dalam pembelajaran geometri. Soal-soal geometri yang diberikan hanya soal-soal rutin saja. Padahal tidak semua soal geometri merupakan masalah. Soal geometri merupakan suatu tantangan apabila soal itu tidak dapat dipecahkan oleh peserta didik dengan suatu procedural rutin yang telah diketahui peserta didik. Untuk menjawab soal tersebut memerlukan analisis untuk menemukan pola dan formula tertentu (Sukayasa, 2009).

Upaya untuk mengembangkan KPMM mahasiswa salah satunya adalah dengan menerapkan model pembelajaran yang sesuai. Model pembelajaran yang mendukung yaitu model SAVI (Somatic, Auditory, Visual and Intellectual). Model pembelajaran SAVI menerapkan pendekatan dengan menggabungkan gerakan fisik dan aktivitas intelektual, sehingga dapat mengaktualkan kemampuan analisis dalam pemecahan masalah (kusumawati,2018). Model Pembelajaran SAVI juga menekankan pada bermaknanya belajar melalui mendengarkan, menyimak, berbicara, presentasi, argumentasi, dan menggunakan kemampuan berpikir (minds on) untuk meningkatkan konsentrasi pikiran termasuk memecahkan masalah dan menerapkannya. Saraswati (2019) memaparkan bahwa model pembelajaran SAVI dapat disesuaikan dengan kondisi pembelajaran yang dinamis, sehingga Kreativitas dan improvisasi peserta didik sangat dibutuhkan. Oleh karena itu, model SAVI sangat sesuai dalam mengembangkan kemampuan pemecahan masalah matematis pada geometri.

Selain model pembelajaran, software dalam pembelajaran geometri sangat berperan penting. Dengan menggunakan teknologi, mahasiswa dapat menghasilkan banyak contoh sebagai cara untuk membentuk dan mengeksplorasi dugaan. Visualisasi dan KPMM juga ditingkatkan dengan interaksi dengan animasi pada software. Geometer's Sketchpad (GSP) merupakan software dinamis yang dapat digunakan untuk mempelajari materi matematika terutama materi geometri. Misalnya, GSP digunakan untuk membuat bentuk unsur-unsur dan bangun geometri dengan. Setelah digambar, Objek geometri yang tampilkan dapat divisualisasikan dari berbagai arah dan ukuran. Selain itu GSP juga dapat menentukan sudut, jarak, keliling, dan luas. GSP dirancang oleh Nicholas Jackiw yang memungkinkan pengguna melakukan kontruksi secara sederhana hingga sangat kompleks, teorema dan hubungan dalam geometri, dan memiliki kemampuan untuk merekam konstruksi mahasiswa sebagai skrip (Bakar, dkk, 2010).

Penelitian ini bertujuan untuk menganalisis perbedaan yang signifikan antara data $N$-gain KPMM yang belajar di kelas pembelajaran Model SAVI dengan Geometer's Sketchpad dan mahasiswa yang belajar di kelas pembelajaran pembelajaran Model SAVI tanpa Geometer's Sketchpad. 


\section{METODE PENELITIAN}

Pada penelitian ini menggunakan Quasi Experimental yang subjek penelitiannya tidak dikelompokkan secara acak, dalam hal ini kelas ditentukan berdasarkan kemampuan yang setara. Untuk memperkuat kesetaraan kemampuan kedua kelas tersebut, dilakukan uji statistik, yang terdiri dari dua kelas penelitian yaitu kelas eksperimen (kelas perlakuan) merupakan kelompok mahasiswa program studi matematika yang pembelajarannya menggunakan model SAVI dengan Geometer's Sketchpad, dan kelompok kontrol (kelas kontrol) adalah kelompok mahasiswa program studi pendidikan matematika yang pembelajarannya menggunakan model pembelajaran SAVI, yang kedua kelas tersebut merupakan mahasiswa semester genap angkatan 2017/2018. Penelitian ini menggunakan dua faktor pengukuran dalam versi faktorial yaitu pretest-postest Nonequivalent Control Group Design dengan desain penelitian untuk kedua kelas adalah sebagai berikut (Sugiyono, 2011):

Tabel 1. Desain penelitian

\begin{tabular}{lccc}
\hline \multicolumn{1}{c}{ Kelas } & Pretes & Treatment & Postes \\
\hline Eksperimen & $\mathrm{O}_{1}$ & $\mathrm{X}_{1}$ & $\mathrm{O}_{2}$ \\
\hline Kontrol & $\mathrm{O}_{1}$ & $\mathrm{X}_{2}$ & $\mathrm{O}_{2}$ \\
\hline
\end{tabular}

Keterangan:

$\mathrm{O}_{1} \quad$ : Pre-tes

$\mathrm{O}_{2} \quad$ :Post-test

$\mathrm{X}_{1} \quad$ : Treatment berupa penerapan Model

SAVI dengan Geometer's Sketchpad

$\mathrm{X}_{2} \quad$ : Treatment berupa penerapan Model SAVI

Instrumen penelitian adalah berupa hasil tes KPMM dari kelas kontrol dan kelas eksperimen. Tes KPMM terdiri dari 6 soal uraian dengan teknik skor holistic scoring rubrics (Cai, Lane dan Jakabscin,1996). Soal pemecahan masalah yang digunakan telah dilakukan uji validitas, reliabilitas, tingkat kesukaran dan daya beda, hasil uji tersebut menujukkan bahwa keseluruhan soal uraian layak digunakan untuk instrument penelitian.

Hasil pretes dan postes terkait KPMM akan diolah menggunakan bantuan software IBM SPSS 21 untuk menelaah peningkatan pemecahan masalah mahasiswa menggunakan Model SAVI dengan Geometer's Sketchpad. Adapun tahapan analisis data adalah sebagai berikut:

1) Memberikan skor jawaban mahasiswa sesuai dengan kunci jawaban dan pedoman penskoran yang digunakan.

2) Membuat tabel skor pretes dan postes mahasiswa kelas eksperimen dan kelas kontrol.

3) Menentukan skor peningkatan pemecahan masalah dengan rumus gain ternormalisasi (Meltzer, 2002).

4) Melakukan uji normalitas untuk mengetahui kenormalan data skor pretes, postes dan n-gain menggunakan uji statistik Shappiro Wilk.

5) Menguji homogenitas varians skor pretes, postes dan n-gain menggunakan uji Levene.

6) Uji Perbedaan Rataan

\section{HASIL DAN PEMBAHASAN}

Data yang diperoleh akan dianalisis -menggunakan uji perbedaan rataan yang bertujuan untuk melihat apakah terdapat perbedaan yang signifikan pada kelas eksperimen dan kelas kontrol. Untuk memenuhi asumsi dari uji perbedaan ratan maka terlebih dahulu dilakukan uji prasyarat yaitu uji normalitas dan uji homogenitas. Apabila data tidak memenuhi asumsi normalitas maka akan dilakukan uji non parametrik Mann-Whitney. Sebaliknya apabila normalitas dan homogenitas terpenuhi maka uji perbedaan rataan akan dilakukan dengan uji 2 Independent Sample ( $t$-test for Equality of Mean).

Uji normalitas untuk data pretes dan postes di kelas eksperiment menghasilkan nilai Sig. kurang dari 0,05 maka $H_{0}$ ditolak. Hal ini berarti bahwa skor pretes dan postes 


\section{$\pi$ (Phi)}

kemampuan pemecahan masalah pada kelas eksperimen tidak berdistribusi normal. Sedangkan pada kelas kontrol nilai pretes maupun postes menunjukkan hasil sebaliknya yaitu data berdistribusi normal.

Nilai ngain dari kelas control dan kelas eksperimen menunjukkan nilai sig. lebih dari 0.05 yang artinya berdistribusi normal.

Tabel 2

Data Hasil Uji Normalitas Skor Pretes, Postes, Ngain

\begin{tabular}{cccccc}
\hline \multirow{2}{*}{ Hasil } & Kelas & \multicolumn{3}{c}{ Shapiro-Wilk } & Kesimpu \\
\cline { 2 - 5 } & & $\begin{array}{c}\text { Statis } \\
\text { tik }\end{array}$ & Df & Sig. & lan \\
\hline \multirow{2}{*}{ Pretes } & Eksperimen & 0,899 & 20 & 0,040 & $\begin{array}{c}\mathrm{H}_{0} \\
\text { ditolak }\end{array}$ \\
\cline { 2 - 6 } & Kontrol & 0,934 & 20 & 0,182 & $\begin{array}{c}\mathrm{H}_{0} \\
\text { diterima }\end{array}$ \\
\hline \multirow{2}{*}{ Postes } & Eksperimen & 0,889 & 20 & 0,025 & $\begin{array}{c}\mathrm{H}_{0} \\
\text { ditolak }\end{array}$ \\
\cline { 2 - 6 } & Kontrol & 0,909 & 20 & 0,060 & $\begin{array}{c}\mathrm{H}_{0} \\
\text { diterima }\end{array}$ \\
\hline \multirow{2}{*}{ Ngain } & Eksperimen & 0,954 & 20 & 0,436 & $\begin{array}{c}\mathrm{H}_{0} \\
\text { diterima }\end{array}$ \\
\cline { 2 - 6 } & Kontrol & 0,922 & 20 & 0,110 & $\begin{array}{c}\mathrm{H}_{0} \\
\text { diterima }\end{array}$ \\
\hline
\end{tabular}

Dari tabel 3 hasil uji homogenitas ngain menunjukkan nilai Sig. yaitu 0,623 dengan demikian $\mathrm{H}_{0}$ diterima, artinya varian skor ngain berasal dari populasi yang homogen.

Tabel 3. Data Hasil Uji Homogenitas Skor Ngain

\begin{tabular}{cccccc}
\hline Hasil & $\begin{array}{c}\text { Levene } \\
\text { Statistic }\end{array}$ & Df1 & Df2 & Sig. & Kesimpulan \\
\hline Ngain & 0,245 & 1 & 38 & 0,623 & $\begin{array}{c}\text { Varian } \\
\text { Homogen }\end{array}$ \\
\hline
\end{tabular}

Teknik statistik yang digunakan untuk menguji perbedaan rataan pretes dan postes dari kelas eksperimen dan kelas kontrol adalah uji Mann-whitney. Dari hasil perhitungan pretes diperoleh nilai Asymp. Siq. (2-tailed) sebesar 0,887, hal ini dapat disimpulkan bahwa tidak terdapat perbedaan KPMM mahasiswa kelas eksperimen dan kelas kontrol. Sementara itu hasil uji perbedaaan rataan untuk data postes menunjukkan nilai Asymp. Siq. (2-tailed) sebesar 0,003 yang artinya adanya perbedaan yang signifikan rerata skor postes KPMM mahasiswa yang menggunakan pembelajaran Model SAVI dengan Geometers Sketchpad dan mahasiswa yang menggunakan pembelajaran Model SAVI tanpa Geometer's Sketchpad.

Tabel 4. Hasil Uji Perbedaan data pretes dan Postes

\begin{tabular}{|c|c|c|c|}
\hline Statistik Uji & PRETES & Kesimpulan & Keterangan \\
\hline $\begin{array}{c}\text { Mann- } \\
\text { whitney U }\end{array}$ & 195,000 & \multirow{4}{*}{$\mathrm{H}_{0}$ diterima } & \multirow{4}{*}{$\begin{array}{c}\text { Tidak } \\
\text { Terdapat } \\
\text { Perbedaan }\end{array}$} \\
\hline Wilcoxon W & 405,000 & & \\
\hline $\mathrm{Z}$ & $-0,143$ & & \\
\hline $\begin{array}{c}\text { Asymp. Siq. } \\
\text { (2-tailed) }\end{array}$ & 0,887 & & \\
\hline Statistik Uji & POSTES & Kesimpulan & Keterangan \\
\hline $\begin{array}{c}\text { Mann- } \\
\text { whitney U }\end{array}$ & 94,000 & \multirow{4}{*}{$\mathrm{H}_{0}$ ditolak } & \multirow{4}{*}{$\begin{array}{l}\text { Terdapat } \\
\text { Perbedaan }\end{array}$} \\
\hline Wilcoxon W & 304,000 & & \\
\hline $\mathrm{Z}$ & $-2,928$ & & \\
\hline $\begin{array}{c}\text { Asymp. Siq. } \\
\text { (2-tailed) }\end{array}$ & 0,003 & & \\
\hline
\end{tabular}

Berdasarkan uji t pada Tabel 5 diperoleh nilai sig. (2-tailed) yaitu 0,002 dan menunjukkan kurang dari 0,05 sehingga $\mathrm{H}_{0}$ ditolak, dapat disimpulkan adanya perbedaan yang signifikan antara data $N$-gain KPMM masalah yang belajar di kelas pembelajaran Model SAVI dengan Geometer's Sketchpad dan mahasiswa yang belajar di kelas pembelajaran pembelajaran Model SAVI tanpa Geometer's Sketchpad.

Tabel 5. Hasil Uji Perbedaan data N-gain t-test for Equality of

\begin{tabular}{|c|c|c|c|c|}
\hline \multicolumn{3}{|c|}{ Mean } & \multirow{2}{*}{$\begin{array}{l}\text { Kesimpul } \\
\text { an }\end{array}$} & \multirow{2}{*}{$\begin{array}{l}\text { Keteranga } \\
\mathrm{n}\end{array}$} \\
\hline$T$ & $D f$ & $\begin{array}{l}\text { Sig.(2- } \\
\text { tailed) }\end{array}$ & & \\
\hline 3,306 & 38 & 0,002 & $\begin{array}{c}\mathrm{H}_{0} \\
\text { ditolak }\end{array}$ & $\begin{array}{l}\text { Terdapat } \\
\text { Perbedaan }\end{array}$ \\
\hline
\end{tabular}

\section{SIMPULAN DAN SARAN}

Berdasarkan analisis data dan pembahasan hasil penelitian yang sudah diuraikan maka diperoleh kesimpulan, Peningkatan KPMM mahasiswa program studi matematika yang belajar pembelajaran model SAVI dengan Geometer's Sketchpad lebih baik dibandingkan mahasiswa yang 


\section{$\pi$ (Phi)}

belajar menggunakan model SAVI tanpa Geometer's Sketchpad.

Berdasarkan analisis dan hasil penelitian, maka penulis mengemukakan beberapa saran sebagai berikut:

1. Pembelajaran model SAVI dengan Geometer's Sketchpad dijadikan salah satu pilihan pendekatan pembelajaran bagi para guru dan dosen untuk meningkatkan kemampuan pemecahan masalah. Hal ini dikarenakan pembelajaran model SAVI dengan Geometer's Sketchpad dapat membantu mahasiswa untuk lebih mudah cepat dalam memahami materi atau konsep baru yang dipelajari.

2. Disadari bahwa tidak ada metode yang tunggal yang dapat digunakan dalam setiap kondisi. Oleh sebab itu, diperlukannya variasi dalam pengajaran. Untuk lebih meningkatkan kemampuan matematis siswa khususnya kemampuan pemecahan masalah, untuk peneliti selanjutnya dapat menggunakan Pembelajaran model SAVI dengan Geometer's Sketchpad dengan software lain.

3. Masalah terbesar dalam penelitian ini adalah keterbatasan waktu, untuk penelitian selanjutnya hendaknya untuk mempertimbangkan keefektifan waktu dalam proses pembelajarannya.

\section{DAFTAR PUSTAKA}

Bakar, K.A. Tarmizi, R.A. Ayub, A.F.M. \& Yunus, A.S.M. (2010). Effect of Utilizing Geometer's Sketchpad on Performance and Mathematical Thinking of Secondary Mathematics Learners: An Initial Exploration. Journal of Educational Technology, 1(3), pp. 20-27.

Bobango, J.C. (1993). Geometry for all student: Phase-Based Instruction. Dalam Cuevas (Eds). Reaching All Students With Mathematics. Virginia: The National Council of Teachers of Mathematics, Inc.
Clements, D.H. \& Battista, M.T. 1992. Geometry and Spatial Reasoning. Dalam Grouws, D.A. (Ed). Handbook of Research on Mathematics Teaching and Learning. New York: MacMillan Publishing Company.

Kusumawati, Nanik. 2018. Peningkatan Hasil Belajar Siswa Kelas V Dengan Model Pembelajaran SAVI Pada Mata Pelajaran IPA di SDN Mangkujayan I Kabupaten Ponorogo. Jurnal Pendidikan Dasar Nusantara, Universitas Nusantara. PGRI Kediri. Vol. 3, No. 2.

Meltzer, D.E. 2002. The Relationship between Mathematics Preparation and Conceptual Learning Grains in Physics: A Possible "Hidden Variable" in Diagnostice Pretes Scores. Dalam American Journal Physics, Vol 70 (12).

Saraswati, Maulana, N. 2019. Pengaruh Model Pembelajaran SAVI ( Somantik, Auditori, Visual, dan Intelektual Terhadap Kemampuan Menulis Karangan Argumentasi Siswa SMA. Jurnal Kajian Pendidikan Dan Pengajaran. Vol 5. No 1.

Shadiq, F. (2004). Penalaran, Pemecahan Masalah dan Komunikasi Dalam Pembelajaran Matematika. Depdiknas Ditjen Pendidikan Dasar dan Menengah PPPG Matematika. Yogyakarta.

Sugiyono. 2011. Metode Penelitian Kuantitatif, Kualitatif dan $R \& D$. Bandung: Alfabeta.

Sukayasa. 2009. Penalaran dan Pemecahan Masalah dalam Geometri. Prosiding Seminar Nasional Penelitian, Pendidikan dan Penerapan MIPA, Fakultas MIPA, Universitas Negeri Yogyakarta, 16 Mei 2009. 